\title{
CONCRETUDE SIMBÓLICA E DESCRIÇÃO ETNOGRÁFICA (SOBRE A RELAÇÃO ENTRE ANTROPOLOGIA E FILOSOFIA)*
}

Luís R. Cardoso de Oliveira

Todas as disciplinas acadêmico-científicas orientadas para a produção de conhecimento mantêm algum vínculo com a filosofia. Tal vínculo é igualmente evidente no caso daquelas disciplinas que tiveram origem no interior da própria filosofia, como a matemática ou a psicologia, assim como no caso daquelas que têm outra origem (e.g. ciências da informação, nutrição etc.), mas que não deixam de dialogar com a filosofia em seus esforços de fundamentação do conhecimento que produzem. No caso da antropologia, esta relação aparece de forma particularmente complexa, na medida em que, além dos vínculos associados ao processo de formação da disciplina ou aos esforços de fundamentação dos resultados de suas investigações, o próprio processo de elaboração da interpretação etnográfica tem uma dimensão filosófica incontornável. Em outra oportunidade procurei caracterizar esta condição disciplinar indicando que ela faz com que a "constituição da disciplina esteja profundamente marcada por uma relação dialética entre a ciência e a filosofia, entre a empiria e a metafísica, ou entre o dado e o significado" (L. Cardoso de Oliveira 1993:67). Se toda pesquisa empírica, qualquer que seja a sua natureza, tem uma dimensão conceitual que condiciona o olhar do pesquisador, na antropologia haveria uma tensão permanente entre o material colhido no campo e o sentido a ele atribuído.

Na tradição francesa, na qual o desenvolvimento da disciplina está fortemente marcado pela Escola Sociológica liderada por Durkheim e Mauss, toda a discussão sobre a relação entre categorias do entendimento e morfologia social se dá em diálogo direto com a filosofia — com filósofos neokantianos, de um lado, e empiristas, de outro (Durkheim 1912) - retomado em alguma medida na discussão sobre a articulação entre práticas e representações sociais. Neste quadro, a síntese desta relação com a filosofia talvez pudesse ser mais bem expressa através da noção de concretude simbólica, que tão bem retrata a trajetória da disciplina de Mauss a Claude 
Lévi-Strauss, também desenhada por Merleau-Ponty (1980:193-206), e que teria levado Lévi-Strauss a afirmar que "os símbolos são mais reais que aquilo que simbolizam" (Lévi-Strauss 2003:29). Pois gostaria de argumentar que o simbólico, foco privilegiado da descrição etnográfica, traz consigo o caráter absolutamente indissociável das dimensões empírica e filosófica da antropologia, ou da relação de internalidade entre dado e conceito na interpretação antropológica. ${ }^{1}$

Se esta indissociabilidade entre dado e significado nunca deixou de ser uma preocupação na tradição francesa, de base fenomenológica, na tradição anglo-americana o tema passou a ser explorado de forma mais sistemática apenas a partir dos anos 1960, quando o chamado corte epistemológico entre sujeito e objeto começa a ser questionado ou relativizado de forma mais incisiva. Primeiramente, no conhecido debate sobre a racionalidade na antropologia inglesa, a partir da crítica de Peter Winch (1964:307-324) à interpretação de Evans-Pritchard (1937) sobre o pensamento místico dos Azande, para dar sentido às práticas de bruxaria do grupo. ${ }^{2}$ Posteriormente, o problema ganha ainda maior amplitude na proposta de Geertz por uma antropologia interpretativa (1973) que, de certa maneira, representa um desdobramento das discussões em torno de uma antropologia simbólica (Dolgin, Kemnitzer \& Schneider 1977).

Em todos os casos o que está em jogo é o reconhecimento do caráter simbolicamente pré-estruturado - ou linguistificado, na vertente interpretativa de base analítica ${ }^{3}$ - do mundo social ou da vida em sociedade e de suas implicações para a interpretação antropológica (veja também Rabinow \& Sullivan 1979). Neste sentido, a chamada antropologia pós-moderna é um segundo desdobramento deste movimento, tendo como foco as dificuldades de validação da interpretação antropológica a partir de critérios estritamente externos à investigação, ou à relação do sujeito cognoscente com o objeto cognoscível, e a centralidade da posição do autor na definição dos resultados da pesquisa (veja Clifford \& Marcus 1986 e a crítica de Trajano Filho 1988). ${ }^{4}$

De todo modo, esta dimensão de autorreflexão sempre presente na pesquisa antropológica, também caracterizada como momento não metódico na produção do conhecimento (R. Cardoso de Oliveira 2000:73-93), tem implicações significativas para a etnografia e marca, num só tempo, (1) a crítica incisiva da disciplina ao etnocentrismo, e (2) o caráter inesgotável da compreensão antropológica. Se o primeiro aspecto chama a atenção para a necessidade de o pesquisador relativizar suas categorias ou pressuposições culturais para entender o outro, evitando equívocos no plano cognitivo e arbitrariedades no plano normativo, o segundo aspecto realça o caráter local 
e contextualizado do conhecimento antropológico, sempre aberto a novas interpretações. A propósito, as novas interpretações não são motivadas apenas por novos olhares, partindo de novos pontos de vista, mas também pelo caráter dinâmico das situações ou eventos etnográficos que se transformam ao longo do tempo, ganhando continuamente novos significados. ${ }^{5}$

Embora a antropologia hoje tenha expandido seu universo de pesquisa para todo tipo de sociedade ou formas de vida humana, não excluindo nenhum tipo de grupo ou segmento social, podendo mesmo ter como objeto o próprio grupo social a que pertence o pesquisador, no processo de formação da disciplina o foco de interesse estava voltado para a compreensão de sociedades radicalmente distintas e usualmente distantes da sociedade do antropólogo - sejam estas sociedades tribais, frequentemente ágrafas e de pequena escala (como a maioria das sociedades pré-colombianas nas Américas), ou segmentos de grandes civilizações, como a Índia, a China e toda ou qualquer forma de organização social situada fora do Ocidente (Dumont 1986). O esforço de descrever e dar sentido etnográfico a estas formas de vida diversas trazia como contrapartida imediata uma questão filosófica: quais seriam as condições de inteligibilidade da etnografia? $\mathrm{Ou}$, como descrever de forma não estereotipada e distorcida as práticas sociais ou as formas de vida vigentes além-mar?

\section{Sobre a inteligibilidade das práticas de bruxaria}

Ainda que questões de inteligibilidade estejam presentes em toda e qualquer descrição etnográfica, motivadas pela preocupação em evitar as distorções do etnocentrismo, sua importância aparece de forma particularmente dramática nos estudos sobre bruxaria, como indicado acima no debate provocado pela crítica de Winch a Evans-Pritchard, por enfocarem práticas totalmente desacreditadas na sociedade do pesquisador, especialmente no meio acadêmicocientífico ao qual pertence. Afinal de contas, dado que estas práticas não podem produzir, aos olhos do pesquisador, os efeitos a elas atribuídos pelos sujeitos da pesquisa, como descrevê-las e dar-lhes sentido etnográfico? No início do século passado, Frazer (1976 [1922]) chega a sugerir que a magia seria produto de um erro cognitivo, posteriormente corrigido pelo pensamento científico que a teria sucedido, no que foi prontamente criticado por Wittgenstein (1979) ${ }^{6}$ Pois, seria a magia um modo de intervenção no mundo similar ou da mesma ordem das intervenções fundamentadas no pensamento científico? Winch é um discípulo de Wittgenstein e se inspira nele em sua crítica a Evans-Pritchard, cuja etnografia também sugere deficiências na 
relação entre pensamento místico e realidade, embora tenha sido produto de cuidadoso trabalho de campo, viabilizando um relato muito mais rico, minucioso e denso do que aquele que encontramos em Frazer.

O debate iniciado por Winch motivou várias intervenções e diversas perspectivas, reveladoras da riqueza e da importância do tema, que poderiam ser sintetizadas na oposição entre perspectivas relativistas e racionalistas na fundamentação da compreensão das sociedades ou das formas de vida estudadas pelos antropólogos (veja nota 1). Entretanto, vou acionar apenas três aspectos do debate para realçar o diálogo com a filosofia: (1) a questão da inteligibilidade e as dificuldades de compreensão do outro; (2) as implicações disto para o status da interpretação antropológica; e (3) a necessidade de apreensão de pelo menos uma dimensão de positividade no ponto de vista nativo, mesmo quando o antropólogo se mantém cético quanto ao poder explicativo deste ponto de vista de forma mais abrangente. Em vista das diferenças e da distância entre as visões de mundo encontradas, respectivamente, nas sociedades do pesquisador e dos sujeitos da pesquisa, conforme indicado acima, é praticamente impossível ao antropólogo produzir um relato convincente do material etnográfico colhido em campo sem demonstrar alguma dimensão de sintonia entre sua interpretação e o ponto de vista nativo. Uma orientação consolidada na disciplina é de que a interlocução com os sujeitos da pesquisa constitui importante fonte de aprendizado, e tem papel absolutamente fundamental na elucidação das interrogações do antropólogo.

O principal ponto de discórdia indicado por Winch está no caráter da distinção proposta por Evans-Pritchard entre pensamento científico, senso comum e pensamento místico em sua etnografia. Se os três tipos de pensamento são apresentados como igualmente lógicos, apenas os dois primeiros teriam respaldo na realidade, pois a suposta referência do pensamento místico na realidade não poderia ser demonstrada. Winch cita dois trechos de artigos de Evans-Pritchard nos quais o antropólogo apresentaria o argumento com clareza:

Noções científicas são aquelas em acordo com a realidade objetiva, tanto em relação à validade de suas premissas como em relação às inferências feitas a partir de suas proposições [...] Noções lógicas são aquelas que, segundo as regras do pensamento, as inferências seriam verdadeiras se as premissas também o fossem, sendo a verdade das premissas irrelevante. [...]

Um pote quebrou durante o cozimento. Isto se deveu provavelmente ao saibro. Vamos examinar o pote e verificar se a causa foi esta. Este pensamento é lógico e científico. Doenças são causadas por bruxaria. Um homem está 
doente. Vamos consultar o oráculo para descobrir quem é responsável. Este pensamento é lógico e não científico (tradução do autor) (Evans-Pritchard 1935 apud Winch 1964:308). ${ }^{7}$

O trecho acima aparece logo após outro no qual Evans-Pritchard compara a explicação europeia com a zande sobre a ocorrência de chuvas para assinalar que ambas são produto de construções sociais, igualmente lógicas, e que não refletiriam de modo algum uma suposta superioridade intelectual do europeu:

Seria absurdo dizer que o selvagem pensa misticamente e que nós pensamos cientificamente sobre a chuva. Ambos os casos envolvem processos mentais similares e, além disso, o conteúdo do pensamento é derivado de forma similar. Mas podemos dizer que o conteúdo social de nosso pensamento sobre chuva é científico, ele está em acordo com fatos objetivos, enquanto o conteúdo social do pensamento selvagem sobre chuva é não científico, pois não está em acordo com a realidade, e pode ser também místico quando assume a existência de forças suprassensíveis (tradução do autor) (Evans-Pritchard 1934 apud Winch 1964:308). ${ }^{8}$

Entretanto, Evans-Pritchard indica com todas as letras que, enquanto o pensamento científico estaria em acordo com a realidade, o pensamento mágico não o estaria. Tal afirmação é questionada por Winch (1964:308), que pergunta se Evans-Pritchard não estaria impondo uma definição de realidade ou critérios de validação próprios do jogo de linguagem da ciência em contextos nos quais estes não se aplicariam, supondo a existência de uma realidade independente de qualquer estrutura simbólica ou da linguagem por meio da qual é articulada.

Em outras palavras, apesar de Winch reconhecer a importância da distinção entre o que é real e aquilo que não o é em qualquer sociedade, independentemente da subjetividade ou das idiossincrasias de qualquer ator, o modo de fazer esta distinção não só varia entre as sociedades no tempo e no espaço, mas também entre instituições da mesma sociedade, como a ciência e a religião bem exemplificariam, ${ }^{9}$ salientando que em todos os casos a distinção seria articulada pela linguagem, e não poderia ser adequadamente acionada fora de seu contexto de uso, a partir de critérios exclusivamente externos. ${ }^{10}$ Trata-se, fundamentalmente, de desvendar o que está em jogo nos atos e nas ações humanas, ou qual é o objetivo e o sentido da ação em foco. Seguindo Wittgenstein, Winch argumenta que sem situar o ato com referência à regra que estaria sendo seguida, ou que estaria orientando a ação do ator, não seria possível entender o evento nem saber o que estaria 
realmente acontecendo. Um antropólogo diria que, sem atentar para o ponto de vista nativo, adequadamente contextualizado, seria difícil evitar o etnocentrismo e compreender as instituições (práticas, representações) de sociedades distantes no tempo ou no espaço.

Como se sabe, Evans-Pritchard chama a atenção para o fato de que os Azande distinguem claramente as ideias de causalidade física e causalidade mágica ou mística - baseada em forças suprassensíveis cuja atuação não pode ser demonstrada por meio de uma cadeia de fatos objetivos empiricamente observáveis. Assim, os Azande explicam que o teto do celeiro caiu porque os cupins comeram as suas bases, mas que tais fatos não explicariam por que o teto caiu exatamente quando fulano de tal, atingido pelo teto, estava sentado no celeiro. Para desvendar este aspecto do evento, os Azande consultam oráculos, cujo funcionamento é bem descrito na etnografia. O que nós classificaríamos como acidente ou infortúnio, os Azande classificam como produto de bruxaria (Evans-Pritchard 1937:63-83). ${ }^{11}$ Diferentemente de Frazer, Evans-Pritchard demonstra convincentemente que as práticas mágicas ou de bruxaria não envolvem qualquer equívoco (lógico ou cognitivo) de seus praticantes, ainda que os efeitos a elas atribuídos não tenham respaldo na realidade.

Mas o famoso antropólogo também afirma que durante sua estada entre os Azande teria orientado suas ações e sua vida de maneira geral a partir das noções de bruxaria vigentes, as quais teriam se mostrado tão satisfatórias e adequadas como as que orientavam sua vida na Inglaterra. Evans-Pritchard não apenas teria aprendido a manipular adequadamente as noções de bruxaria dos Azande e entendido a lógica destas práticas, mas as teria acionado com sucesso para dar sentido ao seu cotidiano, no qual as mesmas teriam se mostrado plenamente efetivas. Anos mais tarde Evans-Pritchard (1976:240-254) oferece uma visão mais favorável à relação entre as noções de bruxaria dos Azande e a realidade que elas representam. Embora mantenha certo ceticismo, o autor afirma reconhecer pelo menos parcialmente a realidade das forças psíquicas nas quais as crenças zande sobre bruxaria se baseiam, e sugere que colocar esta realidade em dúvida não só impediria a compreensão das práticas em estudo, mas inviabilizaria qualquer esforço para dar sentido lógico aos próprios atos do pesquisador em suas interações no campo (:244). É exatamente esta a dimensão de positividade do ponto de vista nativo a que me referi acima, a qual elucida e dá sentido objetivo às formas de vida investigadas pelos antropólogos, tornando a sua apreensão a condição de inteligibilidade da realidade etnográfica.

Sem entrar em questões filosóficas mais abstratas sobre o significado de diferentes modalidades culturais para lidar com o sentido dos acidentes ou 
dos infortúnios, bem como com o sentido de práticas religiosas, como as promessas e as preces, por exemplo - tão presentes nas sociedades ocidentais que deram origem à Antropologia — não seria mais adequado concebê-las como evidências de uma realidade que a ciência não explica satisfatoriamente? Ou, que estejam voltadas para questões de outra ordem?

A descrição etnográfica que, como vimos, tem sempre uma dimensão interpretativa, pois embebida nos símbolos que dão sentido às práticas e às instituições estudadas, procura dar conta de realidades cuja nitidez é por vezes de difícil apreensão. Tais símbolos e categorias nativas são sempre fundamentais para a elucidação de formas de vida locais, e sua compreensão demanda uma relativização das categorias e das pressuposições culturais do pesquisador, que não podem ser desprezadas, mas que precisam ser ressituadas ou recontextualizadas para renovar seu poder explicativo.

Trata-se de um procedimento de autorreflexão, que autores como Louis Dumont (1979) — de orientação maussiana — associam à necessidade de o pesquisador colocar-se em perspectiva, refletindo criticamente sobre o seu ponto de partida, e um autor como Clifford Geertz, inspirado na formulação de Heinz Kohut (um psicanalista), caracteriza como um exercício de colocar em conexão conceitos de experiência próxima com conceitos de experiência distante (1983:57). Na situação de campo, tendo como referência o ponto de vista do pesquisador, os primeiros representariam os conceitos da disciplina e aqueles vigentes na sociedade do antropólogo, enquanto os conceitos de experiência distante fariam as vezes das categorias nativas compartilhadas pelos sujeitos da pesquisa. Para acionar apenas um dos exemplos indicados por Geertz (1983), e que dialoga diretamente com a discussão de Dumont sobre o colocar-se em perspectiva, agora tendo como referência o ponto de vista dos nativos ou sujeitos da pesquisa, estratificação social seria um conceito de experiência distante para os indus, e casta seria um conceito de experiência próxima para os mesmos.

A caracterização de Geertz é particularmente feliz por enfrentar diretamente as questões de inteligibilidade envolvidas na interpretação de práticas ou instituições distantes e estranhas ao antropólogo, a partir do esforço de tradução e compreensão de expressões ou locuções básicas da sociedade estudada. Tendo como referência as reações provocadas pela publicação póstuma dos diários de campo de Malinowski (1989 [1967]), Geertz pergunta: “[...] O que acontece com verstehen (a compreensão) quando einfühlen (a empatia) desaparece?" (1983:56). Com a revelação dos comentários negativos que Malinowski fazia em relação aos seus "informantes" no campo, o mito da completa empatia ou sintonia entre o antropólogo e seus nativos caía por terra de forma definitiva. Como explicar então a capacidade de entender e 
interpretar adequadamente costumes tão diferentes, distantes e estranhos aos olhos do antropólogo?

Ambas as formulações, a de Geertz e a de Dumont, indicam que o objetivo da etnografia não é tornar o antropólogo capaz de ver e pensar como os nativos, a partir de uma sensibilidade especial que lhe permitiria transpor-se para a mente dos sujeitos da pesquisa, e reduziria a noção de empatia à ideia de simpatia (capacidade de identificar-se com o outro), mas acionar conceitos e pressuposições que permitam estabelecer algum nível de interseção com o ponto de vista nativo. A meu ver, o conceito que melhor exprime este movimento interpretativo de apreensão de formas de vida e de visões de mundo distantes no tempo ou no espaço seria o de fusão de horizontes, como elaborado por Gadamer (1994 [1960], 1977). Inspirando-me na formulação deste autor, procurei caracterizar as condições de produção da interpretação antropológica examinando a situação do encontro etnográfico, no qual o pesquisador teria que construir com sucesso uma área de interseção entre o seu universo de referência sociocultural e o dos nativos (L. Cardoso de Oliveira 1993: veja o gráfico na página 73).

Esta imagem do encontro etnográfico procura tematizar o exercício hermenêutico-interpretativo da estrutura de contínuas antecipações que caracterizam o círculo hermenêutico de Schleiermacher a Gadamer, passando por Dilthey, Heidegger e toda uma série de autores associados ao romantismo alemão do século XIX. ${ }^{12}$ A ideia é que, para compreender outras culturas ou formas de vida, assim como para apreender o significado de práticas sociais e eventos sob observação, o antropólogo deve acionar, dentre as pré-concepções que compõem seu horizonte histórico-cultural de referência, aquelas com maior potencial de ressonância no ponto de vista nativo, com o objetivo de desvendar a situação que está sendo examinada. As pré-concepções acionadas permitem ao antropólogo antecipar um significado ao evento ou à situação etnográfica, e seu poder de elucidação é continuamente testado e renovado no esforço de elaboração de interpretações coerentes do respectivo evento ou situação etnográfica como um todo, assim como de suas partes. ${ }^{13}$ Este vai e vem entre parte e todo, a partir das antecipações do intérprete, é o que caracteriza o círculo hermenêutico, que talvez fosse mais bem concebido como uma espiral (Fischer 1985), na medida em que nesse processo o intérprete nunca volta exatamente para o mesmo lugar de onde começou, mas para posições sempre potencialmente mais esclarecidas.

O correlato da fusão de horizontes de Gadamer na proposta de Winch seria a necessidade de o intérprete estender ou ampliar seu universo linguístico-cultural, explorando de forma aberta e criativa, dentre as categorias preexistentes em nosso universo, aquelas que permitam estabelecer um 
ponto de contato produtivo com o universo do outro (Winch 1964:317-319). Em qualquer hipótese, é importante reter que o acesso à compreensão de outras sociedades ou formas de vida depende de nossa capacidade de encontrar ou construir áreas de interseção entre nossas pré-concepções ou categorias e aquelas vigentes no universo pesquisado. Estas frequentemente apontam para significados contraintuitivos (L. Cardoso de Oliveira 2008a) que precisamos ancorar em áreas de interseção suficientemente porosas para produzirmos interpretações coerentes e enriquecedoras da situação ou do evento em foco.

Antes de trazer a discussão dos problemas de inteligibilidade etnográfica ou da dimensão filosófica da antropologia para contextos mais próximos, a partir de meu próprio material de pesquisa, gostaria de abordar brevemente mais um exemplo envolvendo práticas de bruxaria. Refiro-me à interessante etnografia de Favret-Saada (1977) sobre bruxaria na região de Bocage, na França.

Diferentemente das práticas de bruxaria estudadas por Evans-Pritchard entre os Azande, em que elas permeavam quaisquer aspectos da vida ou do cotidiano de todos os membros da sociedade - e falava-se sobre elas o tempo todo, fazendo com que o tema tivesse sido de certa forma imposto ao pesquisador (Evans-Pritchard 1976:242) — na região de Bocage, as práticas de bruxaria e os discursos que lhe davam sentido competiam com práticas e discursos dominantes (da ciência e da religião católica) que procuravam desacreditá-las, não se falando sobre elas com estranhos, sendo muito difícil o acesso a discursos não estereotipados sobre as referidas práticas.

Segundo Favret-Saada, antes de sua pesquisa, a literatura sobre o tema na região resumia-se a artigos sensacionalistas na imprensa e a trabalhos de folcloristas, que apresentavam as crenças e os costumes locais de forma igualmente estereotipada, como características de camponeses atrasados, ingênuos e com pouca instrução. Pois, como seria possível acreditar em bruxas e em seus feitos na contemporaneidade? Receitas e procedimentos exóticos eram publicados como exemplos de superstições características da Idade Média que ainda sobreviviam em Bocage, como os relatos sobre a excêntrica Dame Blonde, que passava a noite com maridos enfeitiçados para livrá-los do feitiço (Favret-Saada 1977:69).

Não obstante, a etnógrafa demonstra que as práticas de bruxaria locais não são acessíveis a partir da perspectiva de um observador externo, como jornalistas e folcloristas se posicionavam, mas apenas de uma das duas posições nativas institucionalmente disponíveis para a interlocução sobre o tema no campo: a de enfeitiçado(a) ou a de "desenfeitiçador(a)" [désorceleur ou désenvoûter] . A terceira posição teoricamente possível, a de feiticeiro(a), 
não estava de fato disponível, na medida em que constituía uma categoria de acusação com a qual ninguém se identificava. O discurso desinteressado sobre o tema, entre atores não envolvidos no caso em foco, suscitava sempre respostas distantes e incrédulas da população, que classificava as respectivas práticas como costumes do passado ou como excentricidades com as quais não se identificavam (Favret-Saada 1977:15-57). A pesquisadora só conseguiu ter acesso a dados sobre casos concretos, vividos pelos interlocutores, quando foi equivocadamente classificada como desenfeitiçadora, e acabou assumindo o papel, ainda que sem muita clareza no início, o qual posteriormente combinou com a posição de enfeitiçada, quando assim identificada pelos interlocutores. A partir desse momento, foi pouco a pouco desvendando os mistérios das práticas de bruxaria em Bocage.

Ao contrário da visão impressionista e exotizada difundida pelos folcloristas, Favret-Saada descreve práticas que ganham vida e sentido no cotidiano da população local, e que se mostram não apenas lógicas, mas muito mais bem sintonizadas com os dramas enfrentados pelos atores do que os discursos da ciência e da religião, que não dão crédito aos seus problemas nem dão atenção adequada às interrogações dos atores. ${ }^{14}$ Como no caso dos Azande, os camponeses de Bocage não têm problemas para aceitar as explicações de médicos e veterinários sobre doenças na família ou em seus animais, assim como explicações técnicas sobre problemas na colheita etc. Entretanto, tais explicações não satisfazem suas demandas de compreensão de infortúnios em série e, ao invés de oráculos como os Azande, os atores acionam desenfeitiçadores para tal.

Neste sentido, é interessante observar que, como demonstra FavretSaada, as consultas com desenfeitiçadores não apenas dão uma resposta imediata aos infortúnios, como também chegam a ter um sentido terapêutico, preenchendo a ausência de significado deixada pelas alternativas interpretativas vigentes, e permitindo uma compreensão mais satisfatória do destino ou das condições de vida de cada um. A própria pesquisadora indica ter experimentado esta modalidade de terapia durante a pesquisa, ao ter frequentado uma desenfeitiçadora durante mais de dois anos, a quem foi conduzida por aqueles que identificaram seu estado de enfeitiçada, e a cuja interpretação submeteu os eventos de sua vida pessoal nas sessões em que era atendida (1977:39).

Diferentemente de folcloristas e de jornalistas, por um lado, assim como de psiquiatras ou profissionais de saúde e de padres, por outro, a etnógrafa levou a sério o ponto de vista dos camponeses de Bocage, procurando dar sentido às fontes de seu sofrimento e aos discursos através dos quais lidavam com os respectivos problemas e tentavam dar conta de suas experiências. 
Assim como no caso das práticas de bruxaria Zande, a interpretação oferecida pela etnógrafa de Bocage não está imune à crítica ou ao debate, mas a concretude da experiência dos atores não pode ser colocada em dúvida.

\section{Filtragem judicial e a invisibilidade do insulto}

Mas, como a literatura antropológica tem demonstrado, a dificuldade de interpretar adequadamente as práticas sociais ou as condições de vida estudadas não aparece apenas em pesquisas sobre instituições de eficácia duvidosa aos olhos do mundo acadêmico-científico, como a bruxaria, nem somente em etnografias sobre sociedades distantes e com costumes estranhos ao pesquisador. Como veremos, mesmo etnografias sobre instituições centrais para o funcionamento do Estado nas sociedades modernas podem revelar dificuldades interpretativas e sentidos surpreendentes.

Minha pesquisa em um Juizado de Pequenas Causas em Massachusetts, nos Estados Unidos, por exemplo, revelou que um determinado tipo de causa era sistematicamente mal compreendida e mal administrada no âmbito do Juizado. ${ }^{15}$ Refiro-me em especial às causas que demandavam reparação por agressão a direitos de caráter ético-moral, cujos atos de desrespeito não podiam ser traduzidos de forma adequada em evidências materiais e, portanto, eram de difícil apreensão nas audiências judiciais. Caracterizei tais atos de desrespeito como insultos de ordem moral, contrastando-os com quebra de direitos de ordem estritamente legal, claramente positivados. Mais tarde esta distinção veio a ser a chave de minha comparação sobre demandas de direitos e de cidadania no Brasil, em Quebec e nos Estados Unidos (L. Cardoso de Oliveira 2002/2011).

No âmbito do Juizado, as demandas de reparação por insulto apareciam de maneira mais clara nas causas que requeriam indenizações de até 50 dólares, pois na melhor das hipóteses (nestes casos), se tudo desse certo para o autor da causa na audiência judicial, ele receberia no máximo o que teria gasto para levar adiante o processo. ${ }^{16}$ Por que então, nesses casos, as partes faziam questão de recorrer ao Juizado e ter suas demandas ouvidas pelo juiz? Se supuséssemos que o principal objetivo das partes era obter a indenização pleiteada, as ações perderiam sentido, pois significariam sempre uma perda de tempo e, frequentemente, de dinheiro também!

De fato, esses Juizados só admitiam causas cíveis, necessariamente expressas em demandas por indenização, que deveriam ser enquadradas em uma de duas alternativas: (1) demandas de reparação por um tort ou delito civil, ${ }^{17}$ e (2) demandas por quebra de contrato. Em todos os casos o requerente deve apresentar evidências materiais dos prejuízos sofridos para ter reconhecido o 
direito à indenização pleiteada. Além de o insulto caracterizar uma agressão objetiva a direitos que não pode ser adequadamente traduzida em evidências materiais, ele envolve também uma negação ou desvalorização da identidade daquele que se sente agredido (L. Cardoso de Oliveira 2008b:136).

As duas modalidades de enquadramento das causas (tort ou quebra de contrato) representam um forte mecanismo de filtragem, que exclui da análise dos casos tudo aquilo que não puder ser diretamente vinculado aos mecanismos de enquadramento judicial. Esse processo de filtragem é explicitado nos tribunais estadunidenses por meio da expressão to narrow down a case que, na tradição jurídica brasileira, encontra a expressão correlata na ideia de reduzir a termo as demandas. Em ambos os casos trata-se de enquadrar as demandas em formulações jurídicas predefinidas, que permitam selecionar os aspectos (ou os fatos) da disputa aos quais o Juizado pode se dirigir com respaldo institucional para tomar uma decisão.

O fato é que nas tradições jurídicas ocidentais, seja na Common Law ou na Tradição Civilista, a positivação dos direitos e a preocupação em delimitar com maior precisão as fronteiras entre questões de ordem legal e questões de ordem moral fazem do insulto uma agressão quase totalmente invisível. ${ }^{18}$ Deste modo, além das demandas de reparação por insulto não poderem ser formalizadas no Juizado de Massachusetts, onde fiz minha pesquisa, não havia muito espaço para discuti-las até mesmo nas sessões de mediação, cujos procedimentos eram mais flexíveis e assumidamente distintos das práticas judiciais. A propósito, não deixa de ser interessante o fato de que em muitos casos nos quais a percepção de insulto tinha um papel relevante, as partes tinham dificuldade de articular um discurso coerente sobre o fundamento da demanda de reparação sempre que esta não podia ser associada de imediato a um prejuízo material (L. Cardoso de Oliveira 1989:399-440). ${ }^{19}$

Embora as demandas de reparação por insulto e a dificuldade de dar visibilidade a elas no Juizado fossem mais claras nas causas por menos de 50 dólares, cuja motivação não poderia ser adequadamente explicada à luz da indenização pleiteada ou dos prejuízos materiais demandados, elas não deixavam de ter um papel nas causas envolvendo valores maiores, indubitavelmente significativos para as partes. Assim, no caso da "Frustrante Compra de Carro", o autor quer desfazer a transação e demanda indenização de 500 dólares (400 pagos pelo carro e 100 gastos com o conserto), alegando que o carro não estava nas condições combinadas, no que é enfaticamente contestado pelo requerido, mas a motivação para recuperar o prejuízo é substancialmente agravada pelo fato de ele ter se sentido enganado (L. Cardoso de Oliveira 1989:321-326). ${ }^{20}$ Da mesma forma, no caso das "Camisas Perdidas" o querelante quer ser reembolsado em 180 dólares por seis camisas perdi- 
das na lavanderia do requerido e, na sessão de mediação, deixa claro que a decisão de recorrer ao Juizado e demandar o valor de camisas novas (para repor camisas velhas) se deve ao fato de o requerido ter negado qualquer responsabilidade na primeira tentativa de negociação, o que o teria deixado muito irritado com este ato de desrespeito (:383-398). ${ }^{21}$

Do ponto de vista do cidadão, a sensibilidade às agressões por insulto se manifesta em vários contextos de afirmação de direitos e, em pesquisa sobre conflitos administrados na Delegacia do Consumidor em Curitiba, Bevilaqua analisa um caso no qual o consumidor lesado só aceita fazer acordo com o fornecedor se este se comprometer a pedir desculpas formais, após satisfazer plenamente suas demandas de reparação no plano material, as quais eram claramente importantes para o consumidor (2001:319). Em outro lugar, sugeri que as demandas de reparação por insulto estariam associadas à dimensão do reconhecimento que, ao lado das dimensões dos direitos (legais) e dos interesses, estaria presente em quase toda disputa judicial. Enquanto as duas últimas se referem, respectivamente, à observação dos direitos vigentes e à reparação dos prejuízos causados pela quebra destes direitos, a dimensão do reconhecimento estaria relacionada à dignidade do cidadão ou ao direito de ser tratado com respeito e consideração (L. Cardoso de Oliveira 2004:127).

Onde vigora o direito positivo, o Judiciário concentra sua atenção nas dimensões dos direitos e na dos interesses, enquanto a dimensão do reconhecimento parece ser aquela que encontra maiores dificuldades para receber um tratamento adequado, ainda que sua importância seja muito variada nos diversos tipos de causas judiciais. Em algumas delas, como na maioria dos conflitos entre grandes empresas, pode-se dizer que a dimensão do reconhecimento seria mesmo irrelevante. Entretanto, tendo chamado a atenção para aquelas disputas em que as demandas de reparação por insulto se mostravam particularmente significativas, gostaria de enfocar agora alguns conflitos nos quais a sua importância, somada às dificuldades em administrar as respectivas demandas, os tornam quase totalmente ininteligíveis aos olhos do Judiciário, que acaba atribuindo alguma deficiência mental ou graves problemas emocionais aos seus protagonistas.

\section{Como perder o juízo em Juízo}

Minha primeira intuição sobre a fecundidade de explorar a relação entre a dificuldade de o Judiciário administrar demandas de reparação por insulto e o "diagnóstico" judicial de insanidade mental foi motivada pela leitura de um artigo publicado no British Journal of Psychiatry (Lester et al. 2004:352-356). ${ }^{22}$ 
Sob o título de "Unusually persistent complainants", o artigo propunha retomar o tema da paranoia do litigante na identificação de reclamantes especialmente insistentes, e que no passado eram diagnosticados como portadores de psicose delirante (:352). Tal categoria chegou a ganhar definições nos dois principais sistemas de classificação de doenças ${ }_{1}{ }^{23}$ mas teria caído em desuso na segunda metade do século passado por ser considerada uma forma de patologizar aqueles reclamantes com energia e disposição para demandarem seus direitos. A partir de pesquisa realizada em ouvidorias na Austrália, os autores identificaram características comportamentais num grupo de reclamantes classificados como persistentes, as quais coincidiriam em grande medida com os antigos casos de querulous paranoia descritos na literatura psiquiátrica.

A pesquisa da equipe de psiquiatras foi realizada segundo dados coletados por funcionários experientes no encaminhamento de demandas em seis ouvidorias na Austrália, a partir de registros de arquivo, nenhum reclamante tendo passado por exames clínicos. Foi solicitado a estes funcionários que selecionassem casos não mais ativos de reclamantes especialmente persistentes e, para cada caso encontrado, eles deveriam selecionar também o caso seguinte com características similares, envolvendo reclamantes não persistentes de mesmo sexo e faixa etária dos primeiros, para compor um grupo de controle. Para cada caso, eles deveriam responder a um questionário elaborado a partir de consultas com grupos focais de funcionários, e de uma revisão da literatura sobre a paranoia do querelante. Dos 110 questionários distribuídos entre os funcionários das ouvidorias, 96 foram devolvidos com a seguinte composição: 52 referentes a reclamantes persistentes e 44 correspondentes ao grupo de controle (Lester et al. 2004).

O questionário privilegia aspectos externos sobre o modo como as queixas são conduzidas e, quando observam a maneira como os casos são percebidos pelas partes, organizam o material de acordo com critérios excessivamente formais. Como veremos, tais critérios dificultam a apreensão adequada do significado de demandas associadas à dignidade do cidadão, ou à dimensão do reconhecimento, acentuadamente dependentes de processos de elaboração simbólica. Assim, ficamos sabendo que o processamento das demandas dos reclamantes persistentes demora 35 meses em média para ter um desfecho, enquanto o tempo médio das demandas do grupo de controle era de 8,3 meses. Que apenas 23\% dos casos dos persistentes são considerados resolvidos no encerramento do processo, enquanto no grupo de controle esta taxa chega a $87 \%$. Da mesma forma, os persistentes visitam a ouvidoria com maior frequência sem marcar hora ( $31 \%$ vs $4,5 \%$ ), e utilizam maior variedade de instrumentos de comunicação (e-mail, fax, cartas etc.), assim como $60 \%$ destes reclamantes manda mais de 10 cartas, contra $9 \%$ 
do grupo de controle, sendo que $25 \%$ das cartas enviadas por persistentes têm mais de 100 páginas, contra apenas 2,7\% das enviadas pelo grupo de controle. Além disso, $52 \%$ dos persistentes requereram a mudança de atendente ao longo do processo, contra 19\% dos demais.

Todos estes indicadores revelam diferenças significativas entre os dois grupos no que concerne ao empenho dos reclamantes, ou à ênfase com que afirmam seus direitos e à eventual complexidade dos casos, em vista do tempo despendido para processá-los. Mas não dizem nada sobre as causas em si. Embora os dados sobre a natureza do dano e sobre o objetivo da reparação pleiteada revelem números muito parecidos em certos aspectos, as tabelas abaixo também indicam grandes diferenças que precisam ser exploradas para além dos estereótipos comportamentais sugeridos no artigo. ${ }^{24}$

\section{Tabela Comparativa I}

\begin{tabular}{l|c|c} 
Tipo de Dano & $\begin{array}{c}\text { Reclamantes } \\
\text { Persistentes }\end{array}$ & $\begin{array}{c}\text { Grupo de } \\
\text { Controle }\end{array}$ \\
Prejuízo financeiro & $71 \%$ & $72 \%$ \\
Relações afetadas & $25 \%$ & $18 \%$ \\
Funcionamento físico & $15 \%$ & $5 \%$ \\
Danos ao funcionamento social e econômico & $35 \%$ & $9,5 \%$ \\
Danos à autoestima & $40 \%$ & $14 \%$ \\
Danos à saúde em geral & $44 \%$ & $23 \%$
\end{tabular}

\section{Tabela Comparativa II}

\begin{tabular}{l|c|c} 
Reparação Pleiteada & $\begin{array}{c}\text { Reclamantes } \\
\text { Persistentes }\end{array}$ & $\begin{array}{c}\text { Grupo de } \\
\text { Controle }\end{array}$ \\
\hline Compensação financeira & $61 \%$ & $58 \%$ \\
Serviços aprimorados & $42 \%$ & $47 \%$ \\
Desculpas e reconhecimento de maltrato & $67 \%$ & $32 \%$ \\
Reconhecer implicações sociais abrangentes & $39 \%$ & $9 \%$ \\
Reconhecimento público & $25 \%$ & $0 \%$ \\
Processar ou obter demissão do responsável & $43 \%$ & $11 \%$ \\
Exposição pública e humilhação & $14 \%$ & $0 \%$ \\
Justiça baseada em princípios & $60 \%$ & $18 \%$ \\
Querer ter seu dia no tribunal / day in court & $25 \%$ & $4 \%$ \\
Natureza e razões variadas da queixa & $31 \%$ & $0 \%$
\end{tabular}


De fato, os dois primeiros itens de cada tabela não apresentam variação significativa nos números, mas as diferenças nos demais itens são bastante sugestivas. Se não há grandes diferenças na percepção do dano material entre os dois grupos de reclamantes (prejuízo financeiro), ou no que seria necessário para reparar este aspecto da demanda (compensação financeira), as consequências, o sofrimento e as solicitações de reparação mais abrangentes apresentam distinções importantes entre os dois grupos. Os três últimos itens da tabela sobre os tipos de dano são particularmente significativos no que concerne ao sofrimento dos respectivos reclamantes, além de sugerirem diferenças na própria definição dos direitos envolvidos. Os persistentes não só se sentiram mais prejudicados no impacto socioeconômico do dano e nas consequências para a sua saúde, como também indicam ter havido um impacto mais abrangente em relação à sua autoestima (40\% vs 14\%), o que constitui um dos aspectos mais sensíveis das demandas de reconhecimento. A autoestima afeta diretamente a dignidade do cidadão e, como tenho procurado mostrar, tem papel importante nas reivindicações por direito a tratamento com respeito e consideração (L. Cardoso de Oliveira 2002/2011; 2004; 2008b). ${ }^{25}$

A meu ver, o exame da segunda tabela reforça a dificuldade de compreensão mais abrangente, no âmbito das ouvidorias, das demandas enfatizadas pelos reclamantes persistentes. Com exceção da sétima linha, que exige exposição pública e humilhação dos responsáveis pelo dano, revelando um claro desejo de vingança, presente em 14\% das exigências dos persistentes e em nenhuma do grupo de controle, todos os demais itens de reparação podem ser entendidos como medidas em prol da recuperação da dignidade perdida. Este parece ser claramente o caso da solicitação de pedido de desculpas e reconhecimento de tratamento indevido, assim como do reconhecimento público da necessidade de reparação.

A demanda de justiça com base em princípios também aponta na mesma direção, assim como a exigência de "ter seu dia no tribunal" (to have his day in court). Esta última expressão é muito comum no mundo anglófono e, nos tribunais estadunidenses, tem com frequência um significado ambíguo: pode se referir tanto ao direito inalienável de todo cidadão de ter suas reivindicações ouvidas pelo Estado, como se refere também a litigantes cujas demandas são vistas como irrazoáveis, ou sem sentido jurídico, mas que insistem em tê-las julgadas no tribunal. A aparente confusão presente apenas numa parte das causas encaminhadas pelos persistentes, que em 31\% dos casos alterariam a natureza e o fundamento de suas queixas ao longo do processo, também poderia ser entendida como parte do esforço em se fazer entender num contexto adverso ao reconhecimento de direitos associados à dignidade do cidadão. 
Os indicadores que expressam a percepção dos funcionários que atendem aos reclamantes fortalecem o argumento quanto à dificuldade de as ouvidorias australianas processarem satisfatoriamente as demandas de reparação dos reclamantes persistentes, e que eu associaria à problemática da dignidade e do insulto conforme dito acima. Em 31\% dos casos encaminhados por reclamantes persistentes, os funcionários acreditam que não haja perda substancial, contra 9\% dos casos do grupo de controle. Apenas 10\% das queixas dos persistentes seriam apresentadas com coerência e racionalidade nas entrevistas, enquanto $82 \%$ das queixas do grupo de controle satisfariam este aspecto. Da mesma forma, os dados sobre as dificuldades dos funcionários na interação com os persistentes são ainda mais impressionantes: a) em apenas $12 \%$ dos casos a relação é classificada como positiva, contra $86 \%$ dos casos do grupo de controle; b) em $52 \%$ dos casos persistentes o funcionário busca ajuda de um colega mais experiente, contra $2 \%$ dos outros casos; e c) em $48 \%$ dos casos persistentes o funcionário evita contato com frequência, o que não ocorreria em nenhum dos outros casos.

Outras características na apresentação das demandas distinguem os dois grupos de forma acentuada e contribuem para exotizar os reclamantes persistentes: redação longa e difícil na exposição das queixas, retórica de ter sido tratado de forma inaceitável, declarações de terceiros sobre o seu bom caráter, uso de marcadores coloridos e de várias outras formas de ênfase nos textos encaminhados etc. Além disso, aspectos comportamentais quase exclusivos dos reclamantes persistentes vão na mesma direção: ameaças diretas ou indiretas aos atendentes (por escrito, ao telefone ou em pessoa), ameaças de suicídio, uso de expressões excessivamente dramáticas e outros. Gostaria de chamar a atenção aqui para o fato de que, com exceção dos indicadores relativos a ameaças aos funcionários das ouvidorias e de algumas demandas de vingança, que só aparecem nos casos dos reclamantes persistentes, os demais indicadores (salvo pela exigência de reconhecimento público na tabela II) também estão presentes, em alguma medida, nos demais casos, sugerindo algum espaço de interseção entre as demandas expressas nas causas dos dois grupos de reclamantes.

Do meu ponto de vista, a área de interseção relativa às demandas do grupo de controle envolveriam a dimensão temática do reconhecimento e os direitos associados à dignidade do cidadão que, nestes casos ou para estes atores, não teriam a mesma importância presente nos casos dos reclamantes persistentes. Não quero dizer com isto que alguns reclamantes persistentes não tenham problemas psicológicos de gravidade variada, mas que provavelmente, na maioria dos casos classificados como persistentes, o principal problema dos reclamantes estaria na dificuldade em receber atenção adequada para o tipo de demanda encaminhada. Isto não deixaria de ser verdade 
mesmo nos casos em que se pudessem diagnosticar claramente, com base em exames clínicos, quadros de paranoia ou a presença de alguma psicose entre os reclamantes persistentes. Mas, como uma análise mais conclusiva exigiria maior discussão de aspectos substantivos dos casos, que a exposição por meio de indicadores exclusivamente formais não permite, gostaria de concluir minha argumentação com a breve discussão de um caso coletado por mim durante a pesquisa no Juizado de Massachusetts. Assim, poderei caracterizar melhor o déficit de compreensão das demandas de reparação por insulto nos tribunais onde vigora o direito positivo, ou em ouvidorias como as australianas aqui discutidas, assinalando como não é tão difícil ou surpreendente perder o juízo em Juízo.

Trata-se de uma disputa de direitos na locação de imóveis residenciais, envolvendo a caução de segurança (security deposit) comumente cobrada dos inquilinos no ato de locação, e sobre a qual já me referi em outra publicação (L. Cardoso de Oliveira 2002/2011:61-62). O caso é particularmente interessante neste contexto porque a proprietária, cujo comportamento é classificado como totalmente irrazoável pelos funcionários do Juizado, é uma business woman bem-sucedida, plenamente funcional em suas atividades cotidianas e na gestão de seus negócios. Tomei conhecimento do caso quando assistia a sessões na Superior Court do Middlesex County, em Massachusetts, para onde as causas apeladas em meu Juizado eram encaminhadas. ${ }^{26} \mathrm{O}$ caso chamou a atenção não só por ter origem no Juizado, mas também porque a proprietária, que havia formalizado a apelação, não estava representada por advogado e fazia questão de exercer seu direito de autorrepresentação. A sessão foi interrompida e adiada sob protestos veementes da proprietária, pouco depois de ela começar a expor seu caso, por não conseguir apresentar evidências de acordo com as regras procedimentais do tribunal, e por se mostrar incapaz, aos olhos do juiz, de defender seus direitos naquele fórum. ${ }^{27}$

O fato de a proprietária não conhecer as regras procedimentais e ser impedida de exercer o direito de autorrepresentação não me surpreendeu muito, e não fugia ao padrão naquelas circunstâncias, mas sim a sua manifestação de contrariedade e a respectiva repercussão na secretaria do Tribunal. Além de se exceder na contestação da decisão do juiz pelo adiamento, fazendo com que ele tivesse que ameaçá-la de prisão por desacato para encerrar a sessão, a proprietária "bateu-boca" com o secretário do juiz no cartório do Tribunal após a sessão, que a deixou falando sozinha depois de lhe dizer em voz alta: I've had it... I've had it... (cheguei ao meu limite...). Os comentários no cartório após o incidente eram de que a proprietária era uma encrenqueira, emocionalmente perturbada, que just wants her day in court (só queria ter seu dia no tribunal). 
Após observar estas cenas, troquei algumas palavras com a proprietária e examinei os arquivos do Juizado sobre o caso. O processo original havia sido movido pelos ex-inquilinos, que demandavam a devolução da caução de segurança após a desocupação do imóvel, alegando que os problemas eram produto da deterioração padrão pelo uso (wear and tear) do imóvel, e que eles teriam direito à devolução da caução na sua integralidade. Como os direitos ao uso da caução são regulados por leis de aplicação estrita (strictliability), não há muito espaço para flexibilização interpretativa quando o processo é avaliado em audiência judicial. De acordo com a lei, o proprietário só pode reter a caução quando no início da locação assina com o inquilino um documento atestando as condições do imóvel naquele momento, a partir do qual tais condições serão reavaliadas no momento da desocupação. Durante a ocupação, a caução deve ficar depositada numa caderneta de poupança, cujo saldo terá que ser integralmente entregue ao ex-inquilino se não houver reparos justificáveis a fazer. Quando o proprietário não observa estes procedimentos e se recusa a rever sua posição após a recepção de uma carta reclamatória dando-lhe 30 dias para devolver a caução, ele fica sujeito a indenizar o inquilino em até três vezes o valor original da caução.

Foi exatamente isto que aconteceu no caso em foco. Se a proprietária não se conformava em devolver a caução ante a suposta constatação de vários danos produzidos pelos ex-inquilinos em seu imóvel, a decisão judicial concedendo treble damages aos ex-inquilinos deixou-a completamente irada. Ela simplesmente não aceitava o fato de não poder ser indenizada pelos supostos danos no seu imóvel devido a "detalhes" procedimentais, e sua persistência em procurar reverter uma decisão sem articular caminhos jurídicos viáveis, ou mesmo lógicos, tornava suas ações totalmente sem sentido aos olhos do tribunal.

Assim como os reclamantes persistentes australianos, ela havia redigido e enviado ao Juizado longos documentos (um deles com mais de 100 páginas) em apoio às suas demandas, chegando mesmo a encaminhar transcrições de conversas telefônicas com os advogados dos ex-inquilinos, as quais teriam sido ilegalmente gravadas, o que agravava a sua situação jurídica no desenvolvimento do caso. Lendo estes documentos e relacionando-os com algumas de suas falas no tribunal, fica claro que, além dos interesses materiais envolvidos, a proprietária havia tido desentendimentos com os ex-inquilinos ao longo da locação, e acreditava que parte dos danos teriam sido feitos por desleixo intencional, como reação aos referidos desentendimentos. Em uma palavra, ela se sentia abusada pelos ex-locatários e não se conformava com o que lhe parecia ser um respaldo do tribunal aos supostos abusos. Independentemente da maior ou menor adequação dos tribunais modernos para administrar este tipo de conflito, sua existência não é produto 
da insanidade mental de seus protagonistas, e a falta de instrumentos apropriados para administrar conflitos deste tipo ameaça direitos importantes do cidadão, além de poder agravar outros desentendimentos.

De todo modo, a análise destes casos sugere que há problemas de inteligibilidade significativos em seu processamento no âmbito dos tribunais e em outras instituições modernas voltadas para a administração de conflitos. Assim como na discussão sobre as práticas de bruxaria, a comparação com procedimentos científicos não se mostra o melhor caminho para compreendê-las, as demandas de reparação por insulto e os direitos associados ao reconhecimento da dignidade do cidadão também não podem ser adequadamente entendidos pelos critérios vigentes de filtragem judicial ou pela ênfase estrita em direitos positivados. Em ambos os casos o pesquisador deve procurar expandir ou ampliar seu horizonte interpretativo, explorando todas as possibilidades de elucidação a partir da experiência de interação com os sujeitos da pesquisa de forma abrangente. ${ }^{28} \mathrm{~A}$ concretude etnográfica demanda reflexão permanente sobre critérios de inteligibilidade, cultivando assim questões de caráter filosófico para dar conta de situações empíricas bem delimitadas e simbolicamente pré-estruturadas.

Recebido em 28 de março de 2013

Aprovado em 17 de outubro de 2013

Luís R. Cardoso de Oliveira é professor titular no Departamento de Antropologia da Universidade de Brasília e subcoordenador do Instituto de Estudos Comparados em Administração Institucional de Conflitos (INCT-InEAC).

E-mail:<lcardoso@unb.br>

\section{Notas}

* Gostaria de agradecer os comentários de Wilson Trajano Filho e de Alcida Ramos, lembrando que quaisquer problemas interpretativos são de inteira responsabilidade do autor.

${ }^{1}$ Veja a interessante discussão de Winch sobre a relação de internalidade entre ideias e relações sociais, na qual demonstra convincentemente a existência de uma 
interdependência radical entre elas, tornando-as completamente ininteligíveis de forma isolada (1958:121-128).

${ }^{2}$ As principais intervenções neste debate foram disponibilizadas em duas coletâneas organizadas, respectivamente, por Bryan R. Wilson (1970) e Martin Hollise Steven Lukes (1982).

${ }^{3}$ Veja o interessante livro de Roy Howard (1982) sobre três vertentes interpretativas na filosofia ocidental.

${ }^{4}$ Esta problemática do lugar do autor se coloca de maneira inteiramente diferente em antropologias como a brasileira ou a mexicana, por exemplo, que se desenvolveram a partir de pesquisas realizadas dentro das fronteiras dos respectivos países, e nas quais o esforço de compreensão das sociedades tribais estudadas não deixava de estar articulado a uma reflexão sobre a sociedade do próprio pesquisador, na qual conjugava simultaneamente os papéis de intérprete e de ator ou cidadão (veja, inter alia, R. Cardoso de Oliveira 1964; e G. Bonfil Batalla 1987).

${ }^{5}$ Wilson Trajano Filho me chama a atenção para o fato de que, inclusive, interpretações antropológicas anteriores também podem contribuir para alterar o próprio sentido do evento etnográfico em questão. Um caso bem marcante é o poder transformador da interpretação antropológica dos cultos afro-brasileiros sobre o modo de os filhos de santo conceberem a sua própria prática religiosa e os símbolos que são centrais a ela.

${ }^{6}$ A crítica de Wittgenstein teria sido elaborada nos anos 1930, mas publicada postumamente, muitos anos depois.

7 "Scientific notions are those which accord with objective reality both with regard to the validity of their premises and the inferences drawn from their propositions [...] Logical notions are those in which according to the rules of thought inferences would be true were the premises true, the truth of the premises being irrelevant [...] A pot has broken during firing. This is probably due to grit. Let us examine the pot and see if this is the cause. That is logical and scientific thought. Sickness is due to witchcraft. A man is sick. Let us consult the oracles to discover who is responsible. That is logical and unscientific thought".

8 "It would be absurd to say that the savage is thinking mystically and that we are thinking scientifically about rainfall. In either case like mental processes are involved and, moreover, the content of thought is similarly derived. But we can say that the social content of our thought about rainfall is scientific, it is in accord with objective facts, whereas the social content of savage thought about rainfall is unscientific since it is not in accord with reality and may also be mystical where it assumes the existence of supra-sensible forces".

${ }^{9}$ Por exemplo, a realidade de Deus para os cristãos não é contestável ou demonstrável por meio de critérios científicos ou de experimentos empiricamente observáveis. 
${ }^{10}$ A propósito, a discussão de Kuhn (1962) sobre "A Estrutura das Revoluções Científicas" e a incomensurabilidade entre paradigmas científicos traz o problema das distinções entre diferentes definições de realidade para dentro da própria ciência.

${ }^{11}$ Evans-Pritchard distingue bruxaria (witchcraft) de feitiçaria (sorcery or bad magic) no contexto etnográfico dos Zande, identificando o segundo termo com práticas que demandam suporte material ou magia negra (remédios, imprecações etc.), enquanto o primeiro operaria sem suporte material, a partir de atos estritamente psíquicos (1937:21, 387).

${ }^{12}$ Para uma discussão mais detida da tradição hermenêutica como perspectiva, veja, além da obra magna de Gadamer (1994 [1960]), as contribuições de Rickman (1976), Habermas (1977), Bleicher (1980), Howard (1982), e Ricoeur (1992), entre outros.

${ }^{13}$ Gadamer reabilita, em sua obra (1994 [1960], 1977), as noções de pré-conceito, tradição e autoridade - que haviam sido colocadas de lado pela crítica iluminista como condutoras de qualquer esforço compreensivo. Embora este não seja o local adequado para apresentar de forma mais detalhada a articulação entre estas noções e suas implicações, vale apontar que a maior influência neste desenvolvimento é Heidegger e sua definição da pré-estrutura da interpretação composta por três dimensões da antecipação: (1) Vorhabe (pré-ter), baseado no que já temos ou no que já dispomos antecipadamente; (2) Vorsicht (pré-visão) baseado no que prevemos antecipadamente; e (3) Vorgriff (pré-concepção), baseado no que percebemos ou concebemos antecipadamente (Heidegger 1962 [1927]:191).

${ }^{14}$ Tanto a ciência (médicos, veterinários) como a religião (o pároco local ou o exorcista da diocese) descartam qualquer significado para o caráter serial dos eventos atribuídos à bruxaria, não permitindo nenhuma tentativa de elaboração discursiva sobre a situação vivida pelos atores ou sobre seus conflitos.

${ }^{15}$ Trata-se de uma Small Claims Court, e a pesquisa foi realizada nos anos 1980 para a elaboração de minha tese de doutorado (L. Cardoso de Oliveira 1989).

${ }^{16}$ Durante a minha pesquisa, o valor máximo das causas nestes Juizados era de 1.500 dólares e, nas causas de menor valor, o requerente tinha que pagar uma taxa de 8,89 dólares para dar entrada no Juizado, mais cerca de 5 dólares para enviar compulsoriamente cartas de cobrança registradas ao requerido, e outros 5 dólares para pagar o transporte de, pelo menos, duas visitas ao Juizado. Como nas duas visitas o requerente perderia, pelo menos, 5 horas de trabalho que não seriam remuneradas, levando-se em conta que o salário mínimo local à época era de 5 dólares/hora, poderíamos dizer que em nenhuma hipótese seria possível gastar menos de 40 dólares para levar a causa até um desfecho no Juizado.

${ }^{17}$ Tort ou delito civil é uma agressão a direitos de caráter não criminal, que não envolve tampouco a quebra de um contrato: se um vaso cai do parapeito de minha janela e danifica o carro do vizinho, isto caracterizaria um tort, e eu seria responsável pela reparação dos danos causados. 
${ }^{18}$ Veja a seminal contribuição de Berger (1983) em relação à dificuldade de se processar alguém por insulto à honra em sociedades como a estadunidense. Para contrastar estes mecanismos de filtragem judicial com instituições jurídicas não ocidentais, que não enquadram os casos com a mesma rigidez e administram conflitos a partir de um referencial mais amplo, veja as excelentes etnografias de Gluckman (1967 [1955]) e Bohannan (1968 [1957]) sobre sociedades tribais africanas.

${ }^{19}$ No Brasil, os Juizados Especiais têm aceitado demandas de reparação por dano moral, mas estas causas ainda precisam ser mais bem estudadas, e não está claro em que medida elas permitem melhor encaminhamento das agressões a direitos que tenho definido como insulto moral.

${ }^{20}$ Como o autor não tinha evidências que sustentassem suas alegações, o juiz deu ganho de causa ao requerido. Além disso, durante a audiência não foi possível discutir nenhuma das alegações de comportamento inadequado ou ofensivo de parte a parte.

${ }^{21}$ As partes chegaram a um acordo na sessão de mediação no valor dos 180 dólares demandados, mas que seriam pagos em créditos por serviços na lavanderia. Embora a sessão tenha permitido exposição suficiente das alegações sobre a relação entre direitos e interesses das partes de modo a viabilizar um acordo satisfatório, a discussão não chegou a contemplar todas as preocupações explicitadas pelas partes neste aspecto, deixando um déficit de satisfação que impediu a celebração de um acordo plenamente "equânime" em minha classificação dos casos (L. Cardoso de Oliveira 1989:397-440).

${ }^{22}$ Agradeço a Daniel Simião por ter me chamado a atenção para este artigo.

${ }^{23}$ Os dois sistemas seriam os seguintes: ICD - International Classification of Diseases - da WHO; e DSM - Diagnostic and Statistical Manual of Mental Disorders.

${ }^{24}$ As duas tabelas foram elaboradas por mim a partir de dados e indicadores apresentados no artigo de Lester et al. (2004).

${ }^{25} \mathrm{O}$ direito ao reconhecimento tem tido grande espaço na literatura a partir dos anos 1990, com contribuições especialmente importantes de Taylor (1994), Honneth (1996) e Fraser (2003), em que dignidade, autoestima e identidade ganham centralidade nas respectivas formulações.

${ }^{26}$ Quando as partes apelam quanto à decisão prolatada no Juizado, elas são ouvidas de novo, como na primeira instância, agora numa audiência com procedimentos mais formais, perante 12 jurados.

${ }^{27}$ Esses tribunais têm regras estritas de apresentação de evidências, e mesmo um advogado não acostumado a "fazer júri" tem dificuldades de atuar adequadamente nesse fórum. 
${ }^{28}$ Da mesma forma, ante a dificuldade de processar adequadamente estas causas no Juizado, seria interessante que o Judiciário ampliasse alternativas de procedimento e criasse mecanismos de triagem, em associação com outras instituições, de modo a viabilizar melhor compreensão das demandas de reparação por insulto, e desfechos mais sintonizados com as expectativas dos cidadãos.

\section{Referências bibliográficas}

BERGER, Peter. 1983. "On the obsolescence of the concept of honor". In: S. Hauerwas \& A. MacIntire (eds.), Revisions: changing perspectives in moral philosophy. Indiana: University of Notre Dame Press. pp. 172-81.

BEVILAQUA, Ciméa. 2001. "Notas sobre a forma e a razão dos conflitos no mercado de consumo". Sociedade e Estado, XVI (1/2):306-334.

BLEICHER, Josef. (org.). 1980. Contemporary hermeneutics: hermeneutics as method, philosophy and critique. London: Routledge \& Kegan Paul.

BOHANNAN, Paul. 1968 [1957]. Justice and judgment among the Tiv. London: Oxford University Press.

BONFIL BATALLA, Guilhermo. 1987. México profundo: una civilización negada. México: Grijalbo.

CARDOSO DE OLIVEIRA, Luís R. 1989. Fairness and communication in small claims courts. PhD dissertation, Harvard University, Ann Arbor (University Microfilms International, p. 495, order \# 8923299).

- 1993. "A vocação crítica da antropologia". Anuário Antropológico, 90:67-81. Rio de Janeiro: Tempo Brasileiro.

- 2011 [2002]. Direito legal e insulto moral - dilemas da cidadania no Bra- sil, Quebec e EUA (2. ed., com novo prefácio). Coleção Direitos, Conflitos e Segurança Pública. Rio de Janeiro: Garamond. . 2004. "Honra, dignidade e reciprocidade". In: P. H. Martins \& B. F. Nunes (orgs.). A nova ordem social: perspectivas da solidariedade contemporânea. Brasília: Editora Paralelo 15. pp. 122-135.

2008a. "O ofício do antropólogo, ou como desvendar evidências simbólicas". Anuário Antropológico, 2006:9-30. Rio de Janeiro: Tempo Brasileiro. · 2008b. "Existe violência sem agressão moral?". Revista Brasileira de Ciências Sociais - RBCS, 23(67):135146. Disponível em: http://www.scielo.br/pdf/rbcsoc/v23n67/10.pdf.

CARDOSO DE OLIVEIRA, Roberto. 1996 [1964]. O índio e o mundo dos brancos (4a. ed. com novo posfácio).Campinas: Editora da Unicamp. . 2000. "O lugar - e em lugar - do método". In: O trabalho do antropólogo. Brasília: Paralelo 15-Unesp. pp.73-93.

CLIFFORD, James \& MARCUS, George. (eds.). 1986. Writing culture: the poetics and politics of ethnography. California: University of California Press. 
DOLGIN, Janet L; KEMNITZER, David S. \& SCHNEIDER, David M. (eds.). 1977. Symbolic anthropology: a reader in the study of symbols and meanings. New York: Columbia University Press.

DUMONT, Louis. 1979. Homo hierarchicus: essai sur le système des castes. Paris: Edition Tel Gallimard. . 1986. "The anthropological community and ideology". In: Essays on individualism: modern ideology in anthropological perspective. Chicago: The University of Chicago Press. pp. 202-233.

DURKHEIM, Emile. 1912. Les formes élémentaires de la vie religieuse. Paris: Presses Universitaires de France.

EVANS-PRITCHARD, Edward E. 1934. "LévyBruhl's theory of primitive mentality". Bulletin of the Faculty of Arts, University of Egypt.

. 1935. "Science and sentiment". Bulletin of the Faculty of Arts, University of Egypt. - 1937. Witchcraft, oracles and magic among the Azande. Oxford: The Claredon Press.

- 1976. "Some reminiscences and reflections on fieldwork". Appendix IV to the abridge edition of Witchcraft, oracles and magic among the Azande. Oxford: The Claredon Press. pp. 240-254.

FAVRET-SAADA, Jeanne. 1977. Les mots, la mort, les sorts. France: Gallimard. FRASER, Nancy. 2003. "Social justice in the age of identity politics: redistribution, recognition and participation". In: N. Fraser \& A. Honneth, Redistribution or recognition? A political-philosophical exchange. London: Verso. pp. 7-109.

FRAZER, James. 1976 [1922].The golden bough: a study in magic and religion (abridged edition). London: The MacMillan Press LTD.

FISCHER, Michael. 1985. "Da antropologia interpretativa à antropologia crítica". Anuário Antropológico, 83:55-72. Rio de Janeiro: Tempo Brasileiro.
GADAMER, Hans-Georg.1994 [1960]. Truth and method (second revised edition). New York: The Continuum Publishing Company.

. 1977. "The universality of the hermeneutical problem". In: Philosophical hermeneutics. Berkeley: University of California Press. pp. 3-17.

GEERTZ, Clifford. 1973. "Thick description: toward an interpretive theory of culture". In: The interpretation of cultures. New York: Basic Books Inc. Publishers. pp. 3-30.

. 1983. "From the natives point of view". In: Local knowledge: further essays in interpretative anthropology. New York: Basic Books.

GLUCKMAN, Max. 1967 [1955]. The judicial process among the Barotse of Northern Rhodesia (Zambia). 2. ed. Manchester: Manchester University Press.

HABERMAS, Jürgen. 1977. "A review of Gadamer's truth and method". In: F. Dallmayr \& T. MacCarthy (orgs.), Understanding and social inquiry. Notre Dame: University of Notre Dame Press. pp. 335-363.

HEIDEGGER, Martin. 1962 [1927]. Being and time. New York: Harper and Row Publishers, Incorporated.

HOLLIS, Martin \& LUKES, Steven (eds.). 1982. Rationality and relativism. Cambridge: The MIT Press.

HONNETH, Axel. 1996. The struggle for recognition: the moral grammar of social conflicts. Cambridge, Massachusetts: The MIT Press.

HOWARD, Roy. 1982. Three faces of hermeneutics. Los Angeles: University of California Press.

KUHN, Thomas. 1962. The structure of scientific revolutions. Chicago: The University of Chicago Press.

LESTER, Grant; WILSON, Beth; GRIFFIN, Lynn \& MUL-LEN, Paul E. 2004. "Unusually persistent complainants". 
British Journal of Psychiatry, 184: 352- 356.

LÉVI-STRAUSS, Claude. 2003. "Introdução à obra de Marcel Mauss". In: Sociologia e antropologia. São Paulo: Cosac Naify. pp. 11-46.

MALINOWSKI, Bronislaw. 1989 [1967]. A diary in the strict sense of the term. California: Stanford University Press.

MERLEAU-PONTY, Maurice. 1980. "De Mauss a Claude Lévi-Strauss". In: Merleau-Ponty. Coleção Os Pensadores. São Paulo: Editora Abril Cultural. pp. 193-206.

RABINOW, Paul \& SULLIVAN, William. (eds.). 1979. Interpretive social sciences. A reader. Berkley: University of California Press.

RICKMAN, H. P. (org.). 1976. Dilthey: selected writings. London: Cambridge University Press.

RICOEUR, Paul. 1992. Interpretação e ideologias. Rio de Janeiro: Francisco Alves TAYLOR, Charles. 1994. "The politics of recognition". In: A. Gutmann (org.). Multiculturalism and the politics of recognition. New Jersey: Princeton University Press. pp. 25-73.

TRAJANO FILHO, Wilson. 1988. "Que barulho é esse, o dos pós-modernos?". Anuário Antropológico, 86:133-151. Brasília: Editora Universidade de Brasília/Tempo Brasileiro.

WILSON, Bryan (ed.). 1970. Rationality. Worcester: Basil Blackwell.

WINCH, Peter. 1958. The idea of a social science and its relation to philosophy. London: Routledge and Kegan Paul. - 1964. "Understanding a primitive society". American Philosophical Quarterly, 1:307-324. Urbana-Champaign: University of Illinois Press.

WITTGENSTEIN, Ludwig. 1979. Remarks on Frazer's Golden Bough (edited by Rush Rhees). New Jersey: Humanities Press. 


\section{Resumo}

O artigo procura refletir sobre a relação entre antropologia e filosofia a partir de características centrais da descrição etnográfica e da importância da dimensão simbólica da vida social. Tendo como referência as diferentes manifestações da vida social e a diversidade das sociedades e grupos ou segmentos sociais estudados pelos antropólogos, o artigo examina as condições de inteligibilidade do trabalho etnográfico como uma questão que perpassa a pesquisa antropológica onde quer que ela tenha lugar, impondo permanentemente uma reflexão de caráter filosófico para dar conta de problemas concretos, bem circunscritos e empiricamente delimitados. Neste empreendimento, o texto explora inicialmente as condições de inteligibilidade de práticas de bruxaria estudadas pelos antropólogos, para concluir com uma discussão sobre a inteligibilidade das disputas judiciais e das demandas por direitos em sociedades modernas.

Palavras-chave Antropologia e Filosofia, Inteligibilidade, Bruxaria, Conflitos judiciais, Pequenas causas.

\section{Abstract}

This article reflects on the relation between anthropology and philosophy, starting from the central characteristics of ethnographic description and the importance of the symbolic dimension to social life. Taking as its reference the different manifestations of social life and the diversity of societies and groups, or social segments, studied by anthropologists, the article examines the conditions of intelligibility of ethnographic work as an issue that spans anthropological research wherever it occurs. As such, it permanently imposes a reflection, of a philosophical character, that seeks to account for concrete, well-circumscribed and empirically delimited problems. With this in mind, the article first explores the conditions for the intelligibility of witchcraft practices as studied by anthropologists, and concludes with a discussion on the intelligibility of juridical disputes and the demand for rights in modern societies.

Key words Anthropology and Philosophy, Intelligibility, Witchcraft, Juridical conflicts, Small claims. 